\title{
The Classification of Social Appellations in Chinese and English and the Comparison of their Linguistic Structures
}

\author{
Yong Fang \\ Wuhan Language and Culture Research Center, Jianghan University,
}

Wuhan, P.R. China, Postcode:430056

Email: 875540144@qq.com

* This paper is the one of the initial results of the research project "A study on the Feasibility of Promoting Chinese to Foreigners in China”, which has

been sponsored by the Education Bureau of Wuhan Municipal Government.

\begin{abstract}
Chinese and English social appellations are divided into three categories, which includes general appellation, occupational (job) title and quasi-kinship terms. The linguistic structure of Chinese social appellation is comparatively more complicated and includes seven elements. With its structural simpleness and closeness, English social appellation, on the other hand, has only five elements. None of the defining elements in these two languages is the structural prerequisite that composes a social appellation. The sequence of those elements in Chinese and English differs, and sometimes distributed quite reversely. Significant correlation is found between the linguistic structure of social appellation in Chinese and English and their national cultures.
\end{abstract}

Keywords-Social Appellation, Classification, Linguistic Structure, Comparison between Chinese and English language

\section{INTRODUCTION}

Social appellation is widely used in social interaction which reflects and distinguishes social relations, social roles, degree of respect, degree of familiarity and emotion among speakers in communication. Both Chinese and English nations have their own social appellation systems. The scope and range of reference of Chinese and English social appellations varies with relation to the difference between English and Chinese language as well as their cultures, and embodies different languages and culture connotation.

Recently, domestic scholars have performed extensive research on the domain of social appellation as well as some comparative analysis relating to social appellation systems in Chinese and English. The research has mainly focused on differences between the aspects of semantics and culture (Ren Haitang, Feng Ningxia 2004, Shang Ting 2004, Wang Junxia 2004, Liu Lishan 2006) and has not yet made intensive analysis into the comparison of Chinese and English social appellation from the aspect of linguistic structure. The mere comparison between Chinese and English social appellation from semantics and pragmatics aspects is not complete. From the aspect of linguistics research method, linguistic structure, semantics and pragmatics compose the language triangle of linguistics research (Xin Fuyi 1996). Research on linguistic structure serves as an important basis for the research on meaning and value of a language. Therefore, it is not integrated and scientific to compare only the language meaning and value of Chinese and English social appellation systems without any study on their linguistic structure. This essay makes comparisons between Chinese and English social appellation structures, discussing their features, and extracting their structural elements. Based on Small Triangle Research Method, the outcome of this research not only promotes the comparison between Chinese and English social appellation, but also functions as a useful reference for translation of social appellation in these two languages, and for teaching both Chinese and English as foreign languages.

\section{THE ClASSIFICATION OF SOCIAL APPELLATION IN}

\section{CHINESE AND ENGLISH}

Academics in the field maintain varying opinions with regards to the classification of social appellation. Zhu Wanjin (1994) divides Chinese appellations into the following six types, (1) kinship terms; (2) special kinship terms; (3) name, including full name, school name, nick name, Lao(Senior)/Xiao(Junior)/Da(Elder) + family name, alias etc; (4) general appellation; (5) position and rank; (6) zero appellation. Except for the first type, the kinship terms, all the other five Chinese appellation types in the six belongs to the realm of social appellation. Tian Huigang (1998: 292-297) summarizes social appellation system and put into six categories, (1) appellation for social intercourse; (2) appellation for relationship; (3) appellation for position and rank; (4) appellation for respect; (5) appellation for intimacy; (6) quasi-kinship term. Jin Jin'ai (2008: 227-228) classifies social appellation into 7 types, which includes general 
appellation, appellation for position and rank, appellation for respect, quasi-kinship appellation, zero appellation and appellation for intimacy.

Li Qingyuan and Li Xiaohui (2008: 110-111) compare social appellation in Chinese and English from the aspects of the commonly used family name and first name, title, abstract noun as appellation, appellation related to occupation, appellation embodying intimacy and transformation appellation. Chen Linmei (2008: 103-105) divides English and Chinese social appellation into three dimensions, respectively: (1) name appellation; (2) job title appellation; (3) general appellation, person appellation and non-appellation.

Differences between the above mentioned scholars social appellation classifications seem complicated and various at first, however these classifications are essentially the same. On the basis of the above classification, the author classifies English and Chinese social appellations into three categories: (1) general appellation; (2) occupation appellation and job title appellation; (3) quasi-kinship appellation. "General appellation" refers to widely-used appellations on formal occasions or relationship, and among strangers for the purpose of expressing distant human relations, non-distinguished age, occupation, status of the person being addressed. "Occupation appellation" refers to the appellation relative to the occupation of the person being addressed. "Job title appellation" refers to the occupation, job title, academic title, military title and police rank of the person being addressed. "Quasi-kinship appellation" refers to the special appellation used to address non-relatives during social interaction. The following section will compare the linguistic structure of social appellations in Chinese and English on the basis of the classification.

\section{LiNGUISTIC STRUCTURE COMPARISON OF SOCIAL}

\section{APPELLATIONS IN CHINESE AND ENGLISH}

\section{A. Linguistic Structure of Chinese Social Appellations}

The general appellation of Chinese social appellation includes gentleman, Madame, lady, young lady, young fellow, uncle, aunt, comrade, master and so on. Occupation appellation includes teacher, doctor, director, driver, totaling approximately 50 titles. Job title appellation includes the majority of the job titles. Quasi-kinship appellation includes grandpa, grandma, elder uncle, uncle, aunt, elder brother, elder aunt, elder sister, younger sister and so on.

Chinese social appellation is disordered in structure. We categorized Chinese social appellation terms and selected 26 widely-used appellation structures for research, including 10 general appellations, 7 occupation appellations and 9 quasi-kinship appellations. Through careful observation, it is found that there are 7 compositional elements including emotional elements, family name, age, given name, occupation/job title, general appellation, and quasi-kinship appellation. These 7 elements are not the prerequisites of specific Chinese social appellation. In other words, a Chinese social appellation is inevitably composed of these 7 elements but not all of the elements. Please refer to Table 1 for the 7 elements and appellation structure composing Chinese social appellation.

Table I The Structural Elements and Appellation Structure of Chinese Social Appellation

\begin{tabular}{|c|c|c|c|c|c|c|c|c|c|}
\hline $\begin{array}{l}\text { Type, Structural } \\
\text { Element, } \\
\text { Appellation } \\
\text { Structure, } \\
\text { Style }\end{array}$ & $\begin{array}{c}\text { Appellation } \\
\text { Type }\end{array}$ & $\begin{array}{c}\text { (1) } \\
\text { Emotional } \\
\text { Elements }\end{array}$ & $\begin{array}{l}\text { (2) } \\
\text { Age (the } \\
\text { senior and } \\
\text { the junior) }\end{array}$ & $\begin{array}{l}\text { (3) } \\
\text { Family } \\
\text { Name }\end{array}$ & $\begin{array}{l}\text { (4) } \\
\text { Given } \\
\text { Name }\end{array}$ & $\begin{array}{l}\text { (5) } \\
\text { Job } \\
\text { Title }\end{array}$ & $\begin{array}{c}\text { (6) } \\
\text { General } \\
\text { Appellation }\end{array}$ & $\begin{array}{c}\text { (7) } \\
\text { Quasi-kinship } \\
\text { Appellation }\end{array}$ & $\begin{array}{c}(8) \\
\text { Appellation } \\
\text { Style }\end{array}$ \\
\hline Fang Hongjian & General & & & $\sqrt{ }$ & $\sqrt{ }$ & & & & Normal \\
\hline Hongjian & General & & & & $\sqrt{ }$ & & & & Cordial \\
\hline Dear Hongjian & General & $\sqrt{ }$ & & & $\sqrt{ }$ & & & & Intimate \\
\hline $\begin{array}{c}\text { Comrade Fang } \\
\text { Hongjian }\end{array}$ & General & & & $\sqrt{ }$ & $\sqrt{ }$ & & $\sqrt{ }$ & & Formal \\
\hline Comrade Hongjian & General & & & & $\sqrt{ }$ & & $\sqrt{ }$ & & $\begin{array}{l}\text { Intimate, } \\
\text { Formal }\end{array}$ \\
\hline Xiaofang & General & & $\sqrt{ }$ & $\sqrt{ }$ & & & & & Intimate \\
\hline Comrade Xiaofang & General & & $\sqrt{ }$ & $\sqrt{ }$ & & & $\sqrt{ }$ & & $\begin{array}{l}\text { Intimate, } \\
\text { Formal }\end{array}$ \\
\hline
\end{tabular}




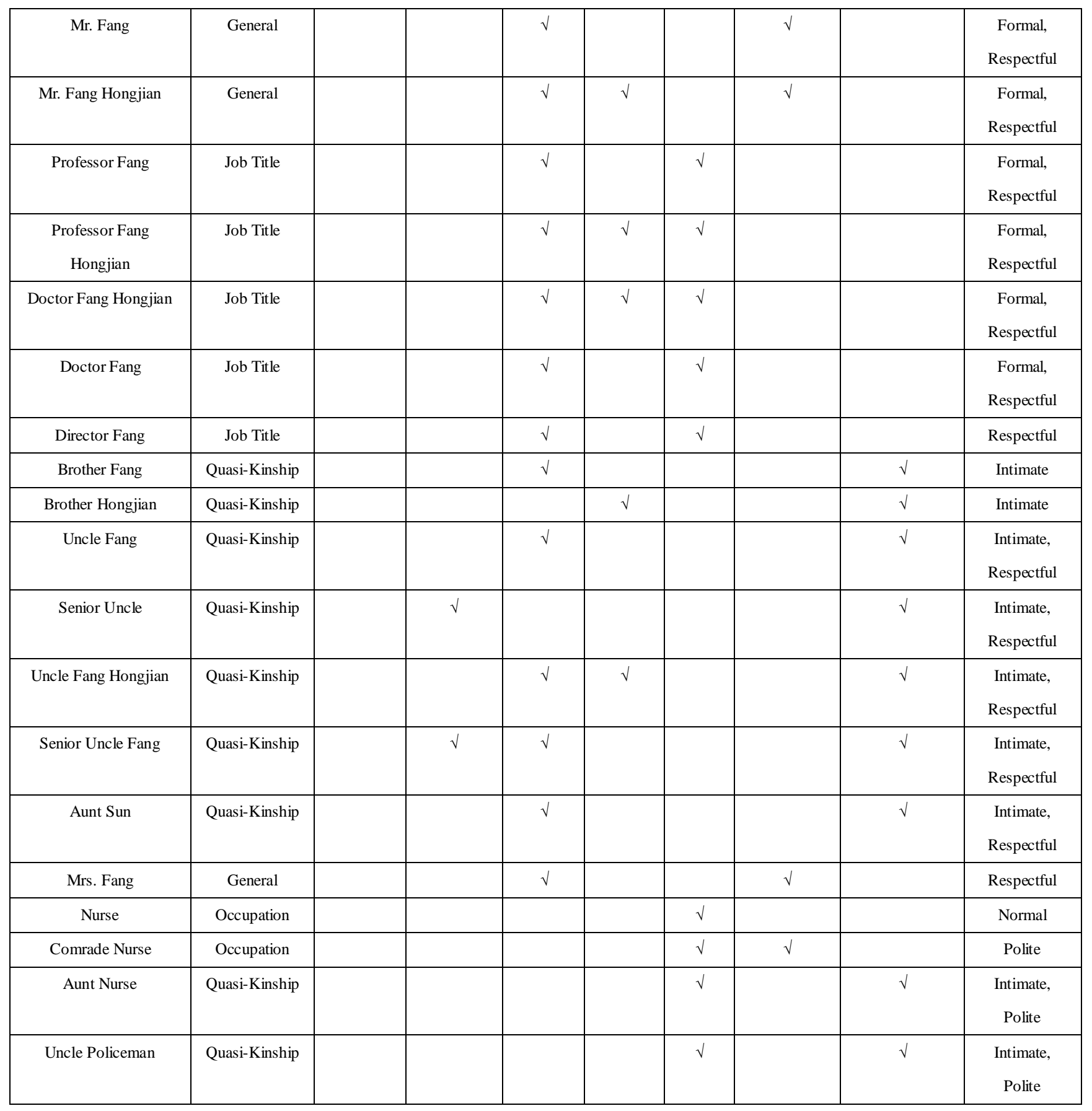

\section{B. Linguistic Structure of English Social Appellations}

General appellation terms in English include Mr., Miss, Mrs., Ms., Sir, Madam, lady, gentleman. The number of English occupation appellations is comparatively less, including two common appellations: professor (Prof. is short for professor) and doctor (Dr. is short for doctor). The number of English job title appellations is limited. They include president (national president, headmaster), ambassador, chairman, governor, dean, director, senator and so on. Compared to Chinese appellations, English social appellations possess characteristics of closure with simple structures and a stable quantity which cannot expand unlimitedly. Using similar methods, we chose 16 widely-used English social appellation structures including 13 general appellations, 3 occupation appellations and job title appellations. Since there is no tradition of using kinship appellation for a non-relative in English speaking countries, this class of structures has not been included in the scope of research. Through observation and study, English social appellation structure elements mainly include the following five: (1) Emotional element, (2) general appellation, (3) occupation appellation and job title occupation, (4) given name, (5) family name. As the same with Chinese social appellation, these 5 elements must or must be command to appear simultaneously in the specific appellation. These five structural elements and appellation structures comprising English social appellation are listed in Table 2 . 
Table II The Structural Elements and Appellation Structure of English Social Appellation

\begin{tabular}{|c|c|c|c|c|c|c|c|}
\hline $\begin{array}{l}\text { Type, Structural } \\
\text { Element, } \\
\text { Appellation } \\
\text { Structure, } \\
\text { Style }\end{array}$ & $\begin{array}{c}\text { Appellation } \\
\text { Type }\end{array}$ & $\begin{array}{l}\quad(1) \\
\text { Emotional } \\
\text { Elements }\end{array}$ & $\begin{array}{l}\text { (2) } \\
\text { Age (the } \\
\text { senior and } \\
\text { the junior) }\end{array}$ & $\begin{array}{c}(3) \\
\text { Family } \\
\text { Name }\end{array}$ & $\begin{array}{c}\text { (4) } \\
\text { Given } \\
\text { Name }\end{array}$ & $\begin{array}{l}\text { (5) } \\
\text { Job } \\
\text { Title }\end{array}$ & $\begin{array}{c}\text { (6) } \\
\text { General } \\
\text { Appellatio } \\
\mathrm{n}\end{array}$ \\
\hline Clinton & General & & & & & $\sqrt{ }$ & Impolite \\
\hline Bill Clinton & General & & & & $\sqrt{ }$ & $\sqrt{ }$ & Serious \\
\hline Bill & General & & & & $\sqrt{ }$ & & $\begin{array}{l}\text { Casual, } \\
\text { Intimate }\end{array}$ \\
\hline Dear Bill & General & $\sqrt{ }$ & & & $\sqrt{ }$ & & Intimate \\
\hline Mr. Clinton & General & & $\sqrt{ }$ & & & $\sqrt{ }$ & $\begin{array}{c}\text { Polite, } \\
\text { Respectful }\end{array}$ \\
\hline Mr. Bill Clinton & General & & $\sqrt{ }$ & & $\sqrt{ }$ & $\sqrt{ }$ & $\begin{array}{c}\text { Polite, } \\
\text { Respectful }\end{array}$ \\
\hline $\operatorname{sir}$ & General & & $\sqrt{ }$ & & & & 礼貌 \\
\hline President Clinton & Job Title & & $\sqrt{ }$ & $\sqrt{ }$ & & & $\begin{array}{l}\text { Polite, } \\
\text { Respectful }\end{array}$ \\
\hline Prof. Noam Chomsky & Occupation & & & $\sqrt{ }$ & $\sqrt{ }$ & $\sqrt{ }$ & $\begin{array}{l}\text { Polite, } \\
\text { Respectful }\end{array}$ \\
\hline Prof. Chomsky & Occupation & & & $\sqrt{ }$ & & $\sqrt{ }$ & $\begin{array}{l}\text { Polite, } \\
\text { Respectful }\end{array}$ \\
\hline Miss Condoleezza Rice & General & & $\sqrt{ }$ & & $\sqrt{ }$ & $\sqrt{ }$ & $\begin{array}{l}\text { Polite, } \\
\text { Respectful }\end{array}$ \\
\hline Miss Rice & General & & $\sqrt{ }$ & & & $\sqrt{ }$ & $\begin{array}{l}\text { Polite, } \\
\text { Respectful }\end{array}$ \\
\hline Ms. Condoleezza Rice & General & & $\sqrt{ }$ & & $\sqrt{ }$ & $\sqrt{ }$ & $\begin{array}{c}\text { Polite, } \\
\text { Respectful }\end{array}$ \\
\hline Mrs. Hilary Clinton & General & & $\sqrt{ }$ & & $\sqrt{ }$ & $\sqrt{ }$ & $\begin{array}{c}\text { Polite, } \\
\text { Respectful }\end{array}$ \\
\hline Mrs. Clinton & General & & $\sqrt{ }$ & & & $\sqrt{ }$ & $\begin{array}{c}\text { Polite, } \\
\text { Respectful }\end{array}$ \\
\hline madam & General & & $\sqrt{ }$ & & & & Polite \\
\hline
\end{tabular}

\section{The Language Structure Comparison of Social \\ Appellations in Chinese and English}

From the above tables we can deduce the following: The Chinese social appellation system has more elements than the English one with regards to language structure including: (1) embody the age of "old" and "young", (2) quasi-kinship appellation. The element of age (old vs. young) may exist in the Chinese Appellation system because of the importance Chinese culture places on the concept of "care for junior, respect for seniority." Quasi-kinship appellation element is an important tool used to maintain social stability and harmony in interpersonal relationship in Chinese culture. Chinese culture emphasizes collective consciousness while English culture tends to focus on individualism. The strong social and collective consciousness in Chinese culture results in the extensive generalization of Chinese kinship appellation in social intercourse. 
From the perspective of structural order, the structure position composing the same elements on Chinese and English appellation is not exactly the same. Frankly speaking, the order of some elements in these two languages is almost reversed. The structure order of Chinese social appellation is: (1) emotional element, (2) family name, (3) the age embodying "old" and "young", (4) given name, (5) occupation/job title, (6) general appellation, (7) quasi-kinship appellation (it is the normal condition, excluding the special structure position order of "senior Mr. Fang"). The structure order of English social appellation is: (1) emotional element, (2) general appellation, (3) occupation/job title, (4) family name, (5) given name. When considering Chinese names, the family name comes first and the given name(s) come last. In China, family names existed prior to the three "emperors" and five "kings" period. This early Chinese society was matrilineal in nature. The earliest family names followed the family name of the mother. Therefore, the family name comes first and the given name comes last according to time sequence. In addition, a family name represents a clan and distinguishes marriage relationships in Ancient Chinese families while given names distinguish nobleness. Compared with the given name, the family name represents the clan and is more important. The Chinese nobleness connotation represented on vocabulary sequence is nobleness comes first and lowliness comes last without reversing the vocabulary sequence. This is represented in the name sequence as well, that is, the family name comes first and the given name comes last. The origin of English names is different from that of Chinese names in that the given name comes first and the family name comes last. There was no family name in England during the period of the Norman Conquest (1066). At that time, people lived in small villages with little exposure to foreigners. Using a single name to refer to an individual was typically enough as there was only one person in the village with that name. With social development and a growing population, villages turned into cities and two or more people with the same name living in the same area became a common phenomenon. Therefore, people added the family name after the given name to distinguish the persons with the same given name----that was given name comes first and family name comes last in English

\section{CONCLUSION}

There is a difference between the structure of social appellation in Chinese and English. Chinese social appellation has seven composing elements while English social appellation only has five. On the structural sequence, some parts of the elements of the two languages represent opposite sequences. The above difference of social appellation in English and Chinese is closely connected to the cultural differences between Chinese and English nations.

\section{REFERENCE}

[1] Cheng Linmei 2008. Analysis of the Difference and Cultural Factors about Appellation in English and Chinese. Journal of Hunan Agricultural University (Social Science Edition), Vol. 9 No.3: 103-105.

[2] Jin Jing'ai, 2008, Analysis of Pragmatic Comparison about Appellation in Chinese and English, Journal of Xiangtan Normal College (Social Science Edition), Vol 30: 227-229.

[3] Li Qingyuan, Li Xiaohui 2008. Comparison of Difference among Appellation Pragmatic Use in the Perspective of Cross Culture in English and Chinese. Journal of Chongqing Normal University (Philosophy and Social Science Edition), 2008 (3) : 110-114

[4] Ren Haitang, Feng Ningxia, Wang Ronghua 2004. The Comparison Analysis on Social Appellation in Chinese and English. Journal of Northwest University (Philosophy and Social Science Edition) Vol .34, No. 1:172-175.

[5] Shang Ting 2004. Comparison Research on Social Appellation in Chinese and English. Journal of Zhaotong Teachers' College, Vol.26, No.6:56-59.

[6] Tian Huigang 1998. Chinese and Western Interpersonal Appellation System. Beijing: Foreign Language Teaching and Research Press.

[7] Wang Junxia 2004. The Relationship between Language and Social Factors from the Perspective of Chinese and English Appellation. Journal of Qiqihar University (Philosophy and Social Science Edition), 2004(1):110-111.

[8] Wang Meiqiong 2008, The Pragmatic Comparison and Translation of Social Appellation in English and Chinese, Journal of Huangshi Institute of Technology (Humanity and Social Science Edition), 2008(1): 69-73

[9] Xing Fuyi 1996. Chinese Grammar. Changchun: Northeast Normal University Press

[10] Zhu Wanjin 1994. Social Linguistics. Changsha: Hunan Education

Press 